\title{
BMJ Open An exploratory analysis of cigarette price premium, market share and consumer loyalty in relation to continued consumption versus cessation in a national US panel
}

\author{
Michael Lewis, ${ }^{1}$ Yanwen Wang, ${ }^{2}$ Zachary Cahn, ${ }^{3}$ Carla J Berg ${ }^{4}$
}

To cite: Lewis M, Wang Y, Cahn Z, et al. An exploratory analysis of cigarette price premium, market share and consumer loyalty in relation to continued consumption versus cessation in a national US panel. BMJ Open 2015;5: e008796. doi:10.1136/ bmjopen-2015-008796

- Prepublication history and additional material is available. To view please visit the journal (http://dx.doi.org/ 10.1136/bmjopen-2015008796).

Received 18 May 2015 Revised 23 August 2015 Accepted 9 October 2015

CrossMark

For numbered affiliations see end of article.

Correspondence to Dr Carla J Berg; cjberg@emory.edu

\section{ABSTRACT}

Introduction: Brand equity and consumer loyalty play a role in continued purchasing behaviour; however, this research has largely focused on non-addictive products without counter-marketing tactics. We examined the impact of brand equity (price premium, market share) and consumer loyalty (switching rates) on smoking cessation (discontinued cigarette purchases for 1 year) among smokers in a consumer panel.

Methods: In Spring 2015, we analysed 1077 cigarette-purchasing households in the Nielsen Homescan Panel. We analysed cessation in relation to brand equity, consumer loyalty, other purchasing behaviours (nicotine intake, frequency),

sociodemographics and tobacco control activities (per state-specific data) over a 6-year period (2004-2009) using Cox proportional hazard modelling.

Results: The sample was $13.28 \%$ African-American; the average income was $\$ 52334$ (SD=31 445). The average price premium and market share of smokers' dominant brands were $\$ 1.31$ (SD=0.49) and $15.41 \%$ $(S D=19.15)$, respectively. The mean brand loyalty level was $0.90(\mathrm{SD}=0.17)$, indicating high loyalty. In our final model, a higher price premium and market share were associated with lower quit rates $(p=0.039)$; however, an interaction effect suggested that greater market share was not associated with lower cessation rates for African-American smokers $(\mathrm{p}=0.006)$. Consumer loyalty was not associated with cessation. Other predictors of lower quit rates included a higher nicotine intake $(p=0.006)$ and baseline purchase frequency $(p<0.001)$. Tobacco control factors were not significantly associated.

Conclusions: Smokers of high-equity cigarette brands are less likely to quit, perhaps due to strong brandconsumer relationships. Thus, continued efforts should aim to regulate tobacco marketing efforts in order to disrupt these relationships to promote cessation.

\section{INTRODUCTION}

There are direct links between exposure to tobacco marketing and tobacco use. Marketing
Strengths and limitations of this study

- This study uses a large national data set of detailed consumer behaviour over several years. However, consumer data are based on household data rather than individual data, and no psychosocial factors that might help explain individual behaviour are available in the data set.

- There is lack of generalisability of the data, as the sample does lack some representativeness of the US population.

- Our definitions of smoker, cessation, brand equity, and consumer loyalty also have limitations.

- We did not include all tobacco control policies in our models, as there was little variability compared to the policies included in the current study.

promotions attract new users, ${ }^{1-5}$ promote continued use, ${ }^{6-8}$ create brand loyalty ${ }^{9}$ and expand tobacco markets. ${ }^{3469}$ In particular, marketers strive to create brands that differentiate products in the same product category. In 2011 , tobacco companies spent $\$ 8.8$ billion marketing tobacco. ${ }^{10}$ As a result, tobacco companies and their products have high brand equity (the economic value of a brand ${ }^{11}$ ). Over the past 5 years, Marlboro has been ranked among the 20 highest equity brands by Interbrand, Millward Brown and Forbes. ${ }^{12}$ Since brand equity is an intangible asset, it is frequently measured through market outcomes such as the 'revenue premiums' achieved by the brand (representing the incremental revenue produced by a brand compared to an unbranded alternative of equal quality). ${ }^{13-15}$ Revenue premium is an attractive measure as it captures both price premiums and market share advantages of a brand. ${ }^{13}$

Creating brand equity and strong brandconsumer relationships are of great importance to marketers, as high-equity brands yield increased loyalty and reduced price 
sensitivity. ${ }^{16}$ This is particularly true among cigarette consumers. ${ }^{17}$ While the marketing literature has focused on how brands influence choice and loyalty within a category, ${ }^{14} 1617$ the question of how brand equity may impact continued usage of a product with addictive characteristics in the face of counter-marketing activity, such as tobacco control activity, has not been addressed. This is a critical issue for tobacco control because cessation rates may be influenced by the existence of brandconsumer relationships in addition to addiction to the physical product. Given that high-equity brands have stronger relationships with consumers, countermarketing activities may decrease overall demand but result in higher market shares for higher equity brands. Survey data indicate that the percentage of adults who smoke has dropped from about $40 \%$ in the 1970 s to $24 \%$ during the decade from 2000 to $2010 .{ }^{18}$ In parallel with this drop, Marlboro's market share has grown from about $10 \%$ in the early 1970 s to over $40 \%$ in $2010 .{ }^{19}$

Policymakers and advocacy groups have adopted a set of strategies intended to counter the marketing tactics used by tobacco companies. ${ }^{20}$ For example, tobacco taxes increase the economic sacrifice required of consumers and can be viewed as a counterweight to tobacco companies' promotional pricing strategies. ${ }^{20}$ Antismoking advertising may reduce the appeal of the overall category by highlighting the health consequences of tobacco. ${ }^{20}$ Smoke-free air policies may make smoking less convenient and may also reduce the value of cigarette branding efforts by limiting opportunities for public consumption. These counter-marketing tactics target the product category rather than the specific brands. As such, they are focused on reducing the appeal of cigarettes in general, but are not typically designed to disrupt the 'relationships' between specific brands and consumers.

We approached the analysis of individual customer behaviour via a perspective that integrates academic work in marketing (brand equity, consumer loyalty) and public health (the socioecological model ${ }^{21-23}$ ). Specifically, we focused on the interplay between measures of cigarette brand equity, customer loyalty and the tobacco control environment in relation to cessation rates. We used consumer panel data augmented with state-specific measures of tobacco control activities to examine the main effects of consumer sociodemographics, consumer purchasing behaviours and tobacco control environment on smoking cessation, as indicated by discontinued cigarette purchasing for at least 1 year. We also examined interaction effects between consumer sociodemographics and consumer purchasing behaviour in relation to this outcome.

\section{METHODS}

Participants and procedures

The Emory University Institutional Review Board approved this study. The consumer purchasing data for our study are derived from the Nielsen Homescan Panel, which provides a de-identified data set including records of consumer packaged goods purchased for a nationally representative panel of US households. The Nielsen Company uses a stratified, proportionate sample for the Homescan Consumer Panel. The design calls for the recruitment of a sample of households that match a selected group of demographic characteristics at the total US major market and 61 geographic areas. The panel is a joint venture between Information Resources, Inc. and Nielsen (http://www.ncppanel.com/content/ ncp/ncphome.html), and access can be purchased. Each household in the panel is provided an optical scanner to scan barcodes of all consumer packaged goods that they purchase, regardless of the outlet (eg, supermarkets, convenience stores, gas stations). This broad coverage is important because smaller retail outlets account for a significant proportion of cigarette sales. ${ }^{24}$

Data were analysed in Spring 2015. To construct our sample, we began with data among 18103 panellists observed continuously from January 2004 to December 2009, which included 5575 cigarette purchasers $(30.8 \%)$. We further restricted our sample to those who: (1) made a cigarette purchase in 2004; (2) made $\geq 1$ cigarette purchase in 2005 or later; (3) purchased $\geq 12$ cigarette packs between 2004 and 2009 and (4) resided in 1 of the top 75 Designated Market Areas (DMAs) in order to track antismoking advertising. These criteria have been used in prior research. ${ }^{25}$ Our final sample included 1077 panellists.

\section{Measures}

Variables included in this analysis included indicators of cessation, brand equity measures, consumer loyalty and important covariates (other purchasing characteristics, sociodemographics, tobacco control metrics).

\section{Cessation}

Our primary outcome was smoking cessation, defined as a smoker not purchasing a pack of cigarettes for at least 1 year. In practice, we define a smoker as a quitter if they discontinued the purchase of cigarettes entirely before the last 12 months of the observation window and did not purchase cigarettes for the remainder of the 6-year period. A recent meta-analyses indicated that only $10 \%$ of smokers relapse after 1 year of abstinence. ${ }^{26}$ In preliminary analyses, we also tested alternative definitions of quitting such as no purchases over a 6 month period. The findings were not significantly altered.

\section{Brand equity}

Since the large number of brands precludes the use of brand-specific indicators, we developed brand equity measures. Our measures of price premiums ${ }^{14}{ }^{27-29}$ and market share premiums ${ }^{14} 30{ }^{31}$ are well established in the marketing literature. For each measure, we used brand level results from 2004 (see online supplementary table A). We calculated brand level price premiums by comparing the average selling price of each brand with 
the selling price of the lowest price brand in 2004. The market share metric was each brand's unit market share. There is significant variation in the brand equity measures. Brands such as Tareyton and Newport can achieve price premiums exceeding $\$ 1.50$ per package (relative to Seneca). Marlboro was the dominant brand with market and revenue shares exceeding $44 \%$. A notable feature of the category is that market shares and price premiums do not exhibit a strong correlation. Tareyton had the largest price premium but a market share of $<1 \%$. This suggests that the factors that enable a brand to charge a price premium may be different from those that drive market share. To determine individual customer preferences for various brands, cigarette purchases in 2004 were used to identify each smoker's most commonly selected brand. The brand equity measures (price premium and market share) of this preferred brand were then used in the analysis of individual-level quit behaviour.

\section{Customer loyalty}

Brand equity metrics cannot capture each individual customer's level of brand loyalty or tendency to switch between brands. The degree to which consumers switch between brands is a common segmentation variable in models of consumer choice. ${ }^{32}$ We first calculated the household brand share for each household in the data (the percentage of total cigarettes purchased devoted to each brand). We then calculated household concentration by summing the square of these shares. For example, if household 1 only purchased brand $\mathrm{A}$ in 2004, then household 1's brand concentration would be 1. In contrast, if household 2 split purchases (in units) evenly between brands A and B, then household 2's brand concentration would be $0.5\left(0.5^{\wedge} 2+0.5^{\wedge} 2=0.5\right)$. This measure of brand concentration is similar to the Herfindahl index used to measure industry concentration. ${ }^{33}$

\section{Purchasing characteristics}

This analysis included two variables to account for nicotine dependence. We included the consumer's previous level of nicotine intake as measured by the machine-tested nicotine levels of the cigarettes purchased in the previous month multiplied by cigarette consumption. We also included frequency, operationalised as the number of packs purchased over the past 6 months. Frequency has been found to be highly predictive of future customer purchasing in a wide range of marketing contexts. ${ }^{34}$

\section{Sociodemographic characteristics}

We included a limited number of demographics available from the Nielsen data. Note that a limiting issue is that the panel operates at the level of the household, making the operationalisation of some sociodemographic factors challenging. We included age as the average age of adult household members. We also included household income and per capita income. In our multivariate models, we chose to include per capita income, as it reflects income to support the number of people in the household. Race was also included. Exploratory analyses indicated that African-American quit rates were significantly different from other races/ ethnicities; thus, we chose to categorise race/ethnicity as African-American versus other. Given that the unit of analysis was the household rather than individuals, we conducted preliminary bivariate analyses to determine how the single member households behaved distinctly

Table 1 Sample characteristics and bivariate analyses examining differences among those with a 1-year cessation versus not among all HHs and among single HHs, respectively

\begin{tabular}{|c|c|c|c|c|c|c|c|c|}
\hline \multirow[b]{3}{*}{ Variables } & \multicolumn{4}{|c|}{ All HHs (N=1077) } & \multirow{2}{*}{\multicolumn{4}{|c|}{$\frac{\text { Single HHs }(\mathrm{N}=241)}{1-\text { Year cessation }}$}} \\
\hline & \multicolumn{4}{|c|}{ 1-Year cessation } & & & & \\
\hline & Mean & No $(76.42 \%)$ & Yes (23.58\%) & p Value & Mean & No $(81.33 \%)$ & Yes (18.67\%) & p Value \\
\hline \multicolumn{9}{|l|}{ Sociodemographics } \\
\hline Age & 57.78 & 57.54 & 58.31 & 0.263 & 61.91 & 61.50 & 63.66 & 0.242 \\
\hline $\mathrm{HH}$ income & 52334 & 50998 & 55156 & 0.109 & 36286 & 35097 & 41463 & 0.189 \\
\hline HH capita income & 24767 & 24687 & 25028 & 0.794 & 36286 & 35097 & 41463 & 0.189 \\
\hline African-American & 13.28 & 15.46 & 8.67 & 0.014 & 12.86 & 13.26 & 11.11 & 0.697 \\
\hline $\mathrm{HH}$ with females & 89.04 & 88.51 & 90.17 & 0.692 & 70.12 & 71.43 & 64.44 & 0.356 \\
\hline \multicolumn{9}{|c|}{ Smoking-related factors } \\
\hline Price premium & 1.31 & 1.31 & 1.29 & 0.519 & 1.343 & 1.343 & 1.25 & 0.222 \\
\hline Market share & 0.15 & 0.15 & 0.16 & 0.817 & 0.12 & 0.12 & 0.12 & 0.957 \\
\hline Loyalty & 0.90 & 0.90 & 0.92 & 0.093 & 0.92 & 0.92 & 0.95 & 0.347 \\
\hline Nicotine intake & 344.67 & 344.84 & 292.40 & 0.406 & 343.72 & 343.88 & 282.46 & 0.178 \\
\hline Frequency & 25.10 & 25.10 & 27.25 & 0.057 & 27.92 & 27.92 & 29.95 & 0.310 \\
\hline \multicolumn{9}{|c|}{ Tobacco control factors } \\
\hline Price+tax & 3.53 & 3.53 & 3.68 & 0.044 & 3.58 & 3.58 & 3.61 & 0.849 \\
\hline Anti-ad GRPs & 236.39 & 236.30 & 253.40 & 0.530 & 252.85 & 252.60 & 348.04 & 0.241 \\
\hline Smoke-free policies & 0.65 & 0.65 & 0.86 & $<0.001$ & 0.58 & 0.58 & 0.68 & 0.582 \\
\hline
\end{tabular}


from multiple adult households. On the basis of these results (table 1), household composition was not included in the final model. Note that the number of declared singles in the sample is relatively small.

\section{Tobacco control environments}

We supplemented the individual consumer information with data on cigarette excise taxes, antismoking advertising rating points and smoke-free restrictions matched to the zip codes of each panellist. Cigarette excise taxes were obtained from the Tax Burden on Tobacco Report, ${ }^{35}$ which provides detailed information on federal, state and local tax rates and effective dates. For simplicity, we assumed that a smoker purchased only from stores located in the same state that he or she lived in and matched the federal, state and local cigarette excise taxes, respectively.

For antismoking advertising, we matched each smoker to a specific DMA based on his or her zip code. We obtained data on adult-targeted antismoking advertising gross rating points from AC Nielsen for all cable and network television in each DMA. Rather than directly including antismoking advertising, we created a variable that defines the stock of health advertising. ${ }^{36}$ Each month, the current stock of antismoking advertising was calculated as the sum of the current gross rating points and the previous stock multiplied by a decay factor of 0.95. ${ }^{37} 38$ (Robustness checks using decay factors with 0.85-0.95 resulted in similar findings.) Note that, because DMAs might include multiple states, to calculate the average advertising level for a state, we took the average of the advertising exposure across all the counties in the focal state. The advertising stock variables were initialised using DMA level gross rating points for the period from 2000 to 2004.

To assess smoke-free restrictions, each smoker was matched to their respective state's level of smoke-free policies in four common venues-restaurants, bars, private workplaces and government workplaces-from the CDC's STATE tracking studies. In each venue, smoke-free restrictions were assigned one of three values: 0 for no restriction, 0.5 for partial restriction and 1 for a complete restriction. We took the average of the smoke-free restrictions in the four venues to describe a state's smoke-free policy level.

\section{Data analysis}

We conducted descriptive analyses and estimated survival models focused on cessation outcomes. ${ }^{39}$ In our analyses, duration was the time until quitting; censoring occurred if an individual had not quit prior to the end of the observation period. We examined the main effects of the brand equity metrics and customer loyalty measures; other purchasing characteristics; sociodemographics and tobacco control environment factors on cessation. Interaction effects among sociodemographic characteristics and consumer purchasing behaviour variables were also examined in relation to cessation. Analyses were conducted using STATA V.12.

\section{RESULTS}

\section{Participant and purchasing characteristics}

Table 1 shows the sociodemographic and purchasing characteristics of the sample of smokers along with the 1-year quit rates. The sample of smokers was $13.28 \%$ African-American, and the average income was \$52 334 ( $\mathrm{SD}=31$ 445; range 5750-170 833).

In terms of the 'brand equity' measures, the average price premium and market share of smokers' dominant brands were $\$ 1.31(\mathrm{SD}=0.49$; range $0-3.58)$ and $15.43 \%$ ( $\mathrm{SD}=19.31$; range $<0.01-44.41$ ), respectively. This means that the average smoker's preferred brand was priced at about $\$ 1.30$ more than the lowest priced cigarettes on the market and had approximately a $15 \%$ market share. The mean brand loyalty level was $0.90(\mathrm{SD}=0.17$; range $0.33-1.00)$, indicating that the average panellist was extremely loyal to a single brand.

Bivariate analyses indicated that, among all households, those with a 1-year cessation were less likely to be African-American $(\mathrm{p}=0.014)$, had a higher price+tax $(\mathrm{p}=0.044)$ and were in environments with greater smoke-free policies $(\mathrm{p}<0.001)$. No significant differences were found in relation to cessation among single adult households.

\section{Brand equity and brand loyalty}

Table 2 provides estimation results from two Cox proportional hazard models for 1 year cessation. The first model is a baseline formulation that includes the sociodemographic variables, measures of brand equity and consumer loyalty, and tobacco control environment variables described above. We then conducted preliminary analysis examining potential interactions between multiple versus single member households, age and race by brand equity and consumer loyalty measures on the outcome of cessation. While age and household composition did not yield significant findings, interactions with race did. The second model includes separate interactions between the brand equity and customer loyalty variables and the African-American household indicator.

In the baseline specification of model 1 , the estimation results suggest that measures of brand equity were associated with lower quit rates. The price premium HR was 0.684 ( $p=0.024)$, and the market share HR was marginally significant at $0.99(\mathrm{p}=0.091)$. The price premium HR implies that a smoker who chose a brand priced at $\$ 1$ higher than the lowest priced cigarette had a quit rate that was $31.6 \%$ lower than that of a smoker of average priced cigarettes. The market share effect implies that, as the market share increased by $1 \%$, the quit rate was $0.6 \%$ lower. Notably, including both the price premium and market share premium measures resulted in an improved fit relative to including only the price premium variable 
Table 2 Estimation results from Cox proportional hazard models predicting 1 year quit rates

\begin{tabular}{|c|c|c|c|c|c|c|}
\hline \multirow[b]{2}{*}{ Variables } & \multicolumn{3}{|c|}{ All HHs-model 1} & \multicolumn{3}{|c|}{ All HHs-model 2} \\
\hline & HR & $95 \% \mathrm{Cl}$ & p Value & HR & $95 \% \mathrm{Cl}$ & p Value \\
\hline \multicolumn{7}{|l|}{ Sociodemographics } \\
\hline HH capita income & 1.00 & 1.00 to 1.00 & 0.880 & 1.00 & 1.00 to 1.00 & 0.862 \\
\hline African-American & 0.53 & 0.33 to 0.85 & 0.009 & 1.122 & 0.12 to 10.63 & 0.920 \\
\hline \multicolumn{7}{|l|}{ Smoking-related factors } \\
\hline Price premium & 0.68 & 0.49 to 0.95 & 0.024 & 0.70 & 0.49 to 0.98 & 0.039 \\
\hline Market share & 0.99 & 0.99 to 1.00 & 0.091 & 0.99 & 0.98 to 0.99 & 0.039 \\
\hline Loyalty & 1.81 & 0.82 to 4.02 & 0.143 & 1.99 & 0.86 to 4.59 & 0.105 \\
\hline Nicotine intake & 1.00 & 0.99 to 0.99 & 0.005 & 0.99 & 0.99 to 0.99 & 0.006 \\
\hline Frequency & 0.98 & 0.96 to 0.99 & $<0.001$ & 0.98 & 0.97 to 0.98 & $<0.001$ \\
\hline Price premium $\times$ African-American & - & - & - & 0.92 & 0.42 to 2.03 & 0.833 \\
\hline Market sharexAfrican-American & - & - & - & 1.03 & 1.01 to 1.06 & 0.006 \\
\hline Loyalty×African-American & - & - & - & 0.321 & 0.02 to 4.46 & 0.397 \\
\hline \multicolumn{7}{|l|}{ Tobacco control factors } \\
\hline Price+tax & 1.15 & 0.99 to 1.33 & 0.061 & 1.15 & .997 to 1.34 & 0.055 \\
\hline Monthly anti-ad GRPs* & 1.09 & 0.98 to 1.21 & 0.094 & 1.09 & 0.98 to 1.21 & 0.290 \\
\hline Smoke-free policies & 0.94 & 0.85 to 1.05 & 0.269 & 0.94 & 0.85 to 1.05 & 0.290 \\
\hline
\end{tabular}

Cessation rates over 5 years: $23.58 \%$ ( $n=346 / 1077)$; observations: 57 757; log pseudo-likelihood: -1694.35 for all HHs; -1689.22 for single only HHs.

The analysis has controlled for the panel structure.

*Log used in model.

GRP, gross rating point; $\mathrm{HH}$, household.

according to the Akaike Information Criterion suggesting that the two measures of brand equity operate differently.

In figure $1 \mathrm{~A}$, the quit rate among the top 10 price premium brands was compared to the rest. Smokers who commonly purchased the lower priced brands had a quit rate of $26.52 \%$ by the end of our observation window compared with $24.49 \%$ for smokers who typically selected one of the top 10 priced brands. Figure 1B shows the quit rate for smokers of the top 10 market share brands versus relatively low unit share brands. The quit rate for strong brand smokers was $26.72 \%$ versus $23.27 \%$ for relatively weak brands.

Figure 2 shows the survival plots for smokers who chose cigarette brands with different price premium and unit share levels. The survival rates were derived from the hazard model in table 2 by setting all the other variables to their means. Also, we split the price premium and the unit shares at the median. In this context, 'survival' corresponds to a smoker continuing to smoke, and the quit rate was one minus the survival rate. The figure shows that those who smoked high price premium and high unit share brands were the least likely to quit smoking (20.63\% quit rate at the end of 2009). Those who smoked either high price premium or high unit share brands were less likely to quit $(24.71 \%$ and $23.59 \%$ quit rates, respectively, at the end of 2009). Those who smoked low price premium and small unit share brands were the most likely to quit with an implied quit rate of $28.15 \%$ by the end of 2009 .

Interestingly, in model 1, the individual-level brand concentration HR was larger than 1 but non-significant ( $p=0.143$; table 2$)$. Therefore, while the models suggest that brand equity measures were associated with lower quit rates, low brand switching rates were directionally associated with increased quitting.

In addition, model 1 (table 2) showed that African-American households were less likely to quit smoking $(\mathrm{p}=0.009)$. However, when separate interactions were added for the African-American subpopulation (table 2, model 2), the baseline hazard for African-American became insignificant $(p=0.920)$. The incorporation of the separate interaction yielded some new insights. The market share premium for the overall population shifted from marginally significant $(\mathrm{p}=0.091)$ to significant $(p=0.039)$. The interaction between the market share metric and the African-American indicator yielded a significant positive HR $(p=0.006)$. The combined implication is that both measures of brand equity are correlated with lower cessation rates for the White and other demographic groups. However, for the African-American population, only the price premium metric is correlated with reduced cessation.

\section{Other consumer characteristics}

Other important predictors of cessation included baseline purchasing behaviour. Specifically, both higher frequency of purchase over the past 6 months $(\mathrm{p}<0.001)$ and higher lagged nicotine consumption $(\mathrm{p}=0.006)$ were associated with lower quit rates in the multivariate models (table 2).

\section{Tobacco control environment}

Bivariate analyses indicated that higher price+tax $(\mathrm{p}=0.044)$ and higher smoke-free policies $(\mathrm{p}<0.001)$ predicted cessation (table 1). However, no tobacco control metric was significantly associated with cessation in the multivariate models (table 2). 
A

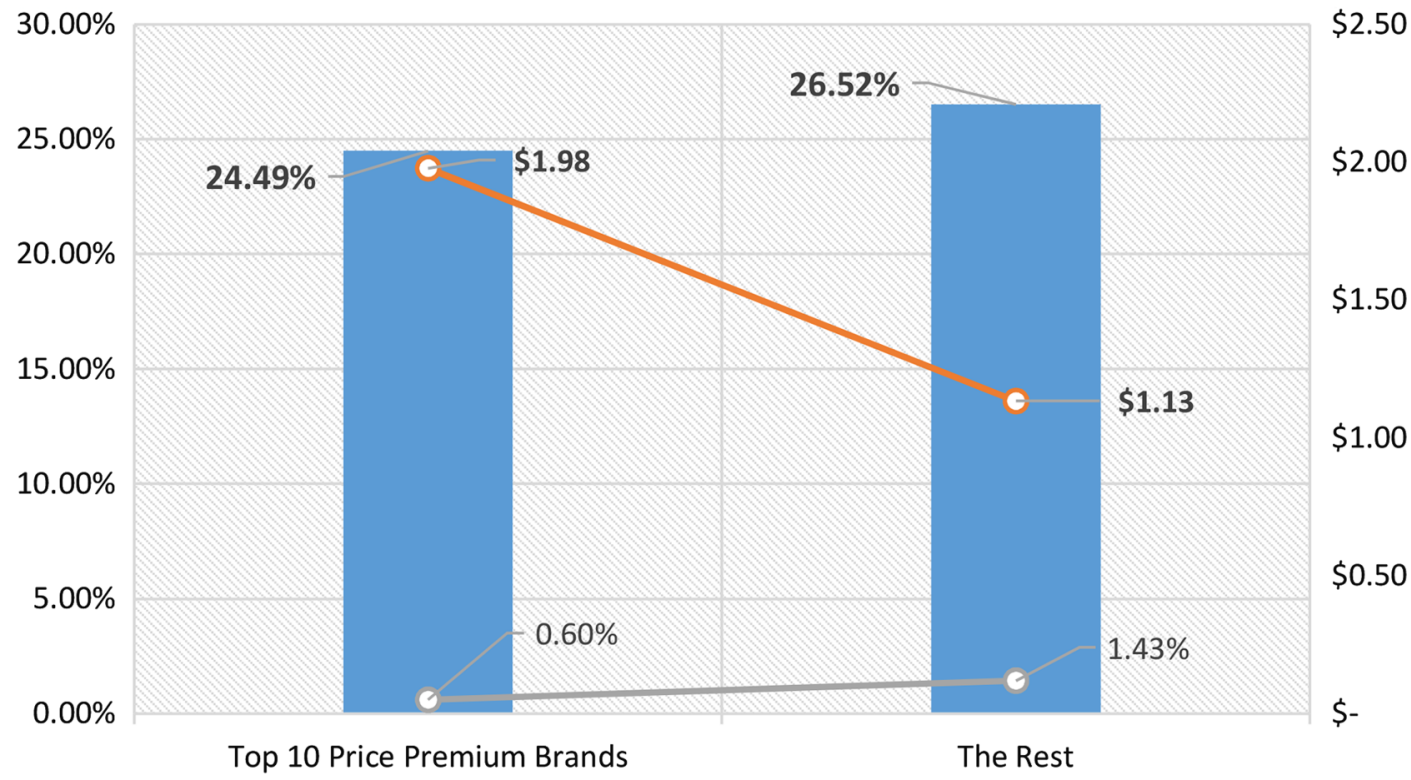

1yr Quit Rate $\quad-0-$ Unit Share $\quad-0$-Price Premium

$\mathrm{B}$

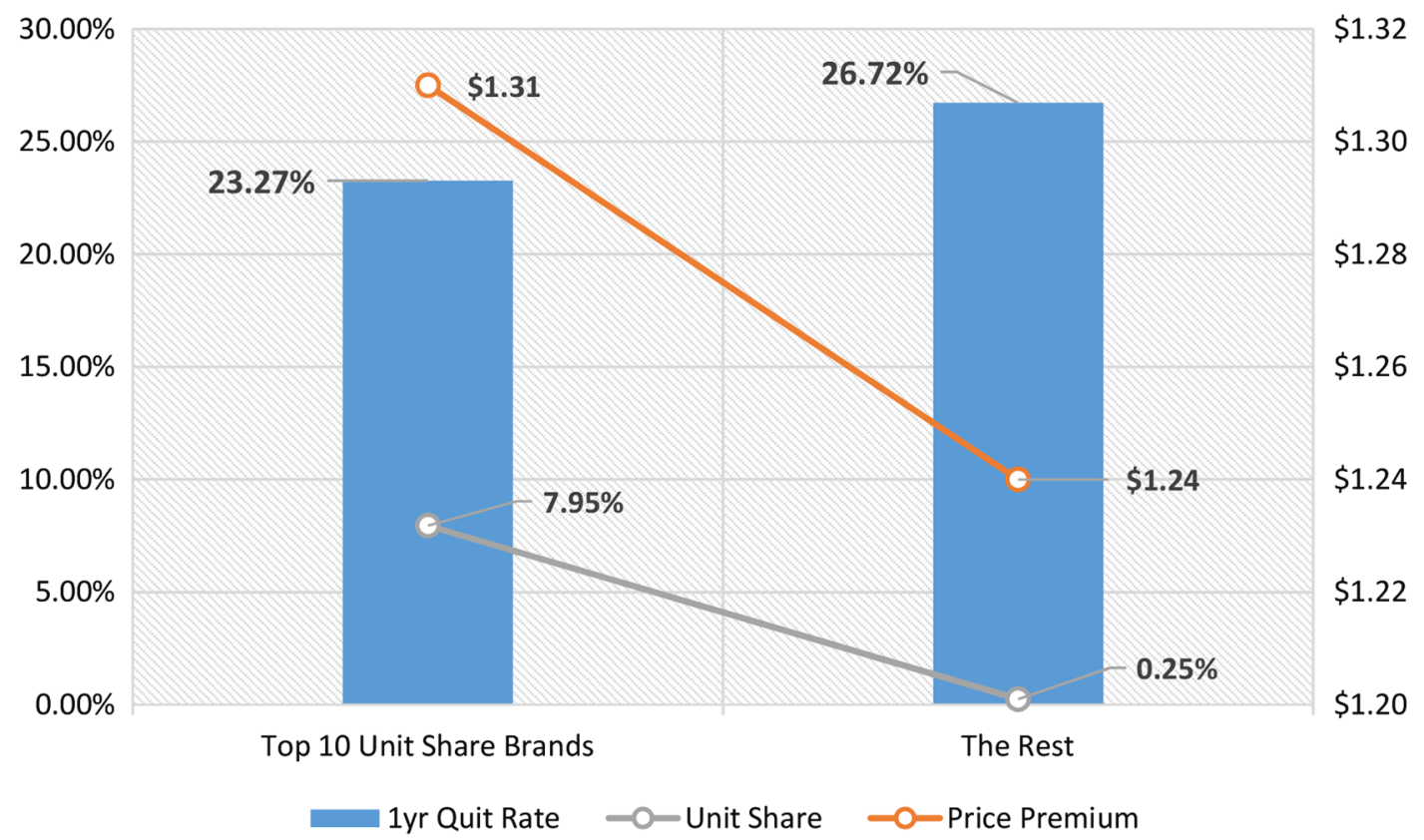

Figure 1 One-year quit rate comparison in $(\mathrm{A})$ the top 10 price premium brands versus other brands and (B) the top 10 unit share brands versus other brands.

\section{DISCUSSION}

This study documented that smokers who prefer higher brand equity products, particularly price premium brands, are less likely to quit smoking. Moreover, while cigarette consumers are highly loyal to their brand (consistent with prior research ${ }^{17}$ ), brand loyalty itself was not a significant predictor of cessation rates. Our speculation is that the high brand equity products decrease cessation because antismoking efforts need to both reduce the preference for the category while simultaneously disrupting the relationship between the brand and the consumer. The lack of a negative effect for the loyalty measure might suggest that the strength of the brandconsumer relationship is more indicated by the 'brand type' than by behavioural loyalty measures. In other words, even if a customer repeatedly buys a low-equity brand, there is unlikely to be a strong psychological bond between the brand and consumer-or at least not a brand-consumer relationship that makes the smoker less likely to quit. 
Figure 2 Cumulative proportion of quitters over time.

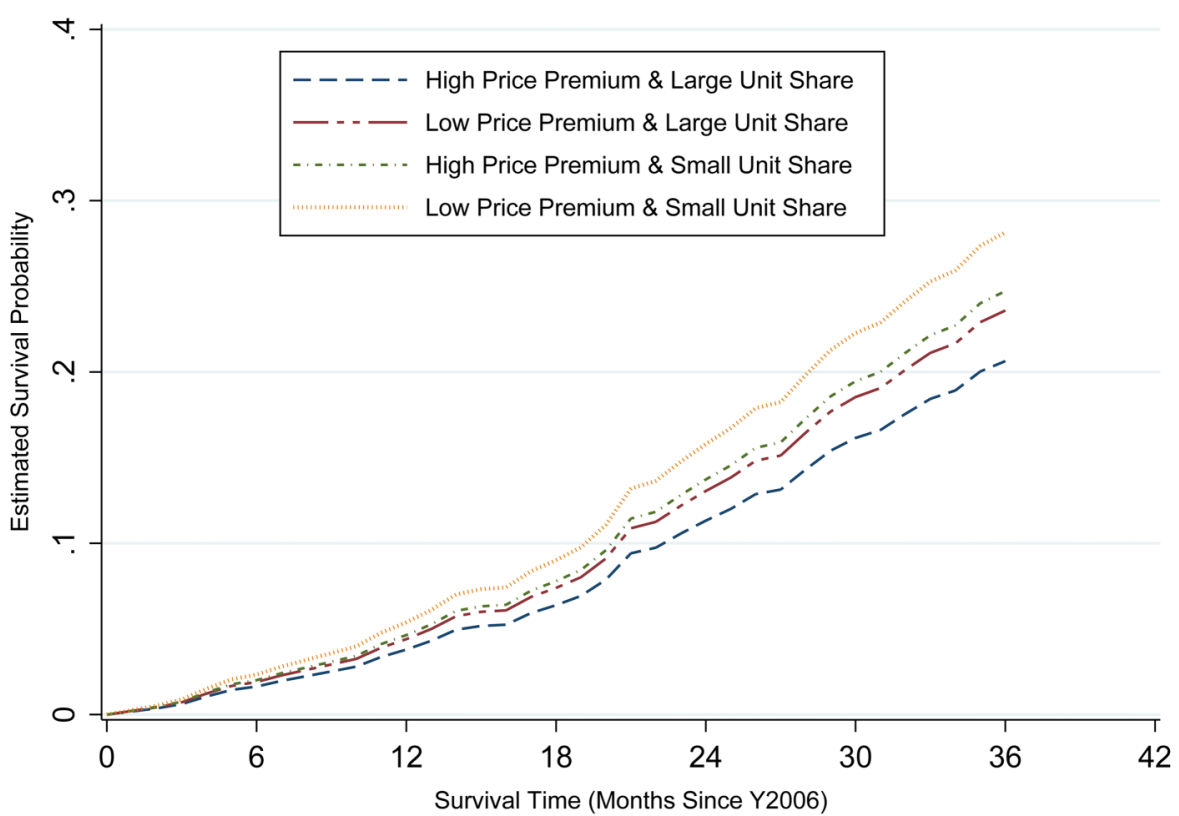

Our results may be reflective of a denormalisation of smoking and an undermining of the legitimacy of the tobacco industry. ${ }^{40}{ }^{41}$ In the context of a social environment where tobacco companies have become viewed as a non-legitimate business, perceptions of a specific brand may play a crucial role in continued purchasing. As such, our findings may indicate that strong brandconsumer relationships may reduce the impact of social stigma and smoking denormalisation on cessation.

Moreover, in response to tobacco regulatory efforts restricting the ways in which the tobacco industry advertises its products, tobacco manufacturers have focused on the remaining avenues for cigarette branding, such as packaging. ${ }^{20}$ Research has revealed the importance of branding, as plain packaging has been shown to impact brand perceptions among current smokers ${ }^{42}$ and adolescents. ${ }^{43}$ Tobacco company documents are also revealing. ${ }^{44}$ Recently, Philip Morris Asia expressed the fear that, with plain packaging, "Philip Morris' products will not be readily distinguishable to the consumer.... [and] will be reduced to the manufacturer of an effectively undifferentiated commodity." 45

Another important finding was that African-Americans were less likely to quit, consistent with prior research. ${ }^{25}$ Interestingly, cessation among African-American smokers was only significantly correlated with the price premium metric, while cessation in households identifying as other races was correlated with both price premium and market share brand equity. This may be due to the high market share of Marlboro cigarettes versus all other brands and the less frequent smoking of Marlboro cigarettes among African-Americans. ${ }^{46}$ This finding merits additional research.

In terms of other predictors, both higher frequency of purchase over the past 6 months and higher lagged nicotine consumption were associated with lower quit rates, also similar to prior research. ${ }^{25}$ Tobacco control activities were not strongly associated with cessation, further building our argument that restricting tobacco marketing is critical.

These findings have implications for research and practice. Researchers should continue to examine branding elements associated with higher brand equity and how this impacts consumer behaviour, particularly as the diversity of tobacco products and marketing strategies continue to increase. In terms of policy, strides towards plain packaging, restrictions at point-of-sale and other efforts to reduce brand equity should be implemented and evaluated.

\section{Limitations}

Research involving this consumer panel has its limitations. First, while the Nielsen panel is intended to provide a representative sample of US consumers, Nielsen notes that, like any consumer panel, young, mobile singles, and very old or wealthy households are difficult to recruit and retain. The unit of analysis being the household is also a limitation; some multiple person households may have multiple smokers. Additionally, the research is limited by the assumptions that purchasing is equivalent to consumption and that all purchases are scanned. The reporting of all purchases may be an especially stringent assumption in the cigarette category, as packages of cigarettes may be purchased at locations such as bars and consumed before the panellist returns home. Finally, individual-level quitting decisions cannot be intuited from household data such as this, further limiting the conclusions that can be drawn on the basis of these data.

Outside of limitations involved with the panel, this research has limitations involving definitions and measures. Our definitions of smoker and cessation are 
somewhat arbitrary. We estimated models using other criteria for these definitions and found our results to be robust. The brand equity metrics also include implicit assumptions. For example, the price premium metric assumes that there is little difference in cost and quality across brands; thus, the cost difference must be reflective of something greater than the inputs needed to make a cigarette. This is, however, a necessary assumption given the lack of objective metrics related to cigarettes. A final limitation is that we did not include all tobacco control policies in our models, as there was little variability compared to the policies included in the current study. Moreover, we did not include smoke-free policies at more local jurisdictions, as state-level norms are highly reflective of more local policy, ${ }^{47}$ and people may spend time in municipalities with varying level of policies at a more local level.

\section{CONCLUSIONS}

These findings add to the accumulating literature suggesting the importance of brand equity in continued product use, specifically in regard to cigarettes which represent a nuanced product category, given their addictive nature and the number of tobacco control activities directed at the entire product category. The novel approach and multilevel data included here provide additional perspective regarding consumer behaviour and the importance of intervening on tobacco marketing.

\section{Author affiliations}

${ }^{1}$ Department of Marketing, Emory University Goizueta Business School, Atlanta, Georgia, USA

${ }^{2}$ Marketing Division, University of Colorado Boulder, Leeds school of Business, Boulder, Georgia, USA

${ }^{3}$ Department of Health Policy and Management, Emory University Rollins School of Public Health, Atlanta, Georgia, USA

${ }^{4}$ Department of Behavioral Sciences and Health Education, Emory University Rollins School of Public Health, Atlanta, Georgia, USA

\section{Acknowledgements The authors would like to thank the funders for their support.}

Contributors All authors contributed to the conceptualisation of the research aims and analytic plan as well as the interpretation of the results. ML and YW conducted the data analysis and contributed to the writing of the manuscript. $\mathrm{ZC}$ contributed to the writing. CJB led the writing of the manuscript and is responsible for the overall reporting of this content.

Funding This work was supported by the National Cancer Institute (U01CA154282-01; PI: Kegler; K07 CA139114; PI: Berg).

Competing interests None declared.

Ethics approval The Emory University Institutional Review Board approved this study.

Provenance and peer review Not commissioned; externally peer reviewed.

Data sharing statement A this is a secondary data analysis, we cite our data source. The data is proprietary and requires either individuals or institutions to purchase access.

Open Access This is an Open Access article distributed in accordance with the Creative Commons Attribution Non Commercial (CC BY-NC 4.0) license, which permits others to distribute, remix, adapt, build upon this work noncommercially, and license their derivative works on different terms, provided the original work is properly cited and the use is non-commercial. See: http:// creativecommons.org/licenses/by-nc/4.0/

\section{REFERENCES}

1. Chen X, Cruz TB, Schuster DV, et al. Receptivity to protobacco media and its impact on cigarette smoking among ethnic minority youth in California. J Health Commun 2002;7:95-111.

2. Evans N, Farkas A, Gilpin E, et al. Influence of tobacco marketing and exposure to smokers on adolescent susceptibility to smoking. J Natl Cancer Inst 1995;87:1538-45.

3. Hanewinkel R, Isensee B, Sargent JD, et al. Cigarette advertising and adolescent smoking. Am J Prev Med 2010;38: 359-66.

4. Lovato C, Watts A, Stead LF. Impact of tobacco advertising and promotion on increasing adolescent smoking behaviours. Cochrane Database Syst Rev 2011;(10):CD003439.

5. Paynter J, Edwards R. The impact of tobacco promotion at the point of sale: a systematic review. Nicotine Tob Res 2009;11:25-35.

6. Gilpin EA, White MM, Messer K, et al. Receptivity to tobacco advertising and promotions among young adolescents as a predictor of established smoking in young adulthood. Am J Public Health 2007;97:1489-95.

7. Choi WS, Ahluwalia JS, Harris KJ, et al. Progression to established smoking: the influence of tobacco marketing. Am J Prev Med 2002;22:228-33.

8. Burton $\mathrm{S}$, Clark L, Jackson $\mathrm{K}$. The association between seeing retail displays of tobacco and tobacco smoking and purchase: findings from a diary-style survey. Addiction 2012;107:169-75.

9. Pucci LG, Siegel M. Exposure to brand-specific cigarette advertising in magazines and its impact on youth smoking. Prev Med 1999;29:313-20.

10. Federal Trade Commission. Federal Trade Commission smokeless tobacco report for 2011. Washington DC, 2013. http://www.ftc.gov/ os/2013/05/130521smokelesstobaccoreport.pdf

11. Korler P, Keller K. Marketing management. 15th edn. Upper Saddle River, NJ: Prentice Hall, 2015.

12. SyncForce. Ranking the brands. 2015. http://www.rankingthebrands com/Brand-detail.aspx?brandID=10 (accessed 12 Mar 2015)

13. Ailawadi KL, Lehmann DR, Neslin SA. Revenue premium as an outcome measure of brand equity. J Mark 2003;67:1-17.

14. Aaker DA. Measuring brand equity across products and markets Calif Manag Rev 1996;38:102-20.

15. Keller KL, Lehmann DR. Brands and branding: research findings and future priorities. Mark Sci 2006;25:740-59.

16. Aaker D. Building strong brands. New York: Free Press, 1995.

17. Dawes J. Cigarette brand loyalty and purchase patterns: an examination using US consumer panel data. J Bus Res 2014;67:1933-43.

18. Gallup Institute. U.S. Smoking Rates Still Coming Down. 2008. http://www.gallup.com/poll/109048/us-smoking-rate-still-comingdown.aspx (accessed 11 Mar 2015)

19. The Wall Street Journal. Altria vulnerable to any slide in Marlboro. 2010. http://www.wsj.com/news/articles/SB1000142405274870331 4904575399632882251718 (accessed 12 Mar 2015)

20. Centers for Disease Control and Prevention. The guide to community preventive services. 2012. http://www. thecommunityguide.org/index.html

21. McLeroy KR, Bibeau D, Steckler A, et al. An ecological perspective on health promotion programs. Health Educ Q 1988;15:351-77.

22. Stokols D. Translating social ecological theory into guidelines for community health promotion. Am J Health Promotion 1996;10: 282-98.

23. Richards L, Potvin L, Kishchuk N, et al. Assessment of the Integration of the ecological approach in health promotion programs. Am J Health Promotion 1996;10:318-27.

24. American Heart Association, Campaign for Tobacco Free Kids. Deadly alliance: how big tobacco and convenience stores partner to market tobacco products and fight life-saving policies. 2012

25. Lewis M, Wang Y, Berg CJ. Tobacco control environment in the United States and individual consumer characteristics in relation to continued smoking: differential responses among menthol smokers? Prev Med 2014;65:47-51

26. Feng $\mathrm{G}$, Jiang $\mathrm{Y}, \mathrm{Li} \mathrm{Q}$, et al. Individual-level factors associated with intentions to quit smoking among adult smokers in six cities of China: findings from the ITC China Survey. Tob Control 2010;19 (Suppl 2):i6-11.

27. Agarwal MK, Vithala R. An empirical comparison of consumer-based measures of brand equity. Mark Lett 1996;7:237-47.

28. Park CS, Srinivasan V. A survey-based method for measuring and understanding brand equity and its extendability. Mark Res 1994;31:271-88.

29. Sethuraman R. A model of how discounting high-priced brands affects the sales of low-priced brands. Mark Res 1996;33: 399-409. 
30. Chaudhuri A, Holbrook MB. The chain of effects from brand trust and brand affect to brand performance: the role of brand loyalty. J Mark 2001;65:81-93.

31. Srinivasan V. Network models for estimating brand specific effects in multi-attribute marketing models. Manag Sci 1979;25:11-21.

32. Blattberg RC, Neslin SA. Sales promotion: concepts, methods, and strategies. Englewood Cliffs, NJ: Prentice Hall, 1990.

33. Tirole J. The theory of industrial organization. Cambridge, MA: MIT Press, 1988

34. Lewis M. Incorporating strategic consumer behavior into customer valuation. J Mark 2005;69:230-8.

35. Orzechowski W. The tax burden on tobacco. Vol 47. Virginia: Orzechowski and Walker, 2012.

36. Little JD. Aggregate advertising models: the state of the art. Operations Res 1979;27:629-67.

37. Hu TW, Sung HY, Keeler TE. Reducing cigarette consumption in California: tobacco taxes vs an anti-smoking media campaign. Am J Public Health 1995;85:1218-22.

38. Hamilton JL. The demand for cigarettes: advertising, the health scare, and the cigarette advertising ban. Rev Econ Stat 1972;54:401-11.

39. Lewis M. Customer acquisition promotions and customer asset value. J Mark Res 2006;43:195-203.

40. Hammond D, Fong GT, Zanna MP, et al. Tobacco denormalization and industry beliefs among smokers from four countries. Am J Prev Med 2006;31:225-32.
41. Chapman S, Freeman B. Markers of the denormalisation of smoking and the tobacco industry. Tob Control 2008;17:25-31.

42. Wakefield MA, Germain D, Durkin SJ. How does increasingly plainer cigarette packaging influence adult smokers' perceptions about brand image? An experimental study. Tob Control 2008;17:416-21.

43. Germain D, Wakefield MA, Durkin SJ. Adolescents' perceptions of cigarette brand image: does plain packaging make a difference? $J$ Adolesc Health 2010;46:385-92.

44. Wakefield M, Morley C, Horan JK, et al. The cigarette pack as image: new evidence from tobacco industry documents. Tob Control 2002;11(Suppl 1):i73-80.

45. Schneider $\mathrm{H}$. Australia's 'plain packaging' stubs out cigarette branding, prompting backlash. 2013. October 29; http://www. washingtonpost.com/business/economy/australias-plain-packagingstubs-out-cigarette-branding-prompting-backlash/2013/10/29/ 317e58cc-3ccd-11e3-a94f-b58017bfee6c_story.html (accessed 21 Jun 2014).

46. Cummings KM, Hyland A, Pechacek T, et al. Comparison of recent trends in adolescent and adult cigarette smoking behaviour and brand preferences. Tob Control 1997; 6(Suppl 2):S31-7.

47. Nykiforuk C, Campbell S, Cameron R, et al. Relationships between community characteristics and municipal smoke-free bylaw status and strength. Health Policy 2007;80:358-68. 